\title{
Numerical Investigation of Heat Transfer Enhancement in a Rectangular Heated Pipe for Turbulent Nanofluid
}

\author{
Hooman Yarmand, ${ }^{1}$ Samira Gharehkhani, ${ }^{1}$ Salim Newaz Kazi, ${ }^{1}$ \\ Emad Sadeghinezhad, ${ }^{1}$ and Mohammad Reza Safaei ${ }^{2}$ \\ ${ }^{1}$ Department of Mechanical Engineering, University of Malaya, 50603 Kuala Lumpur, Malaysia \\ ${ }^{2}$ Young Researchers and Elite Club, Islamic Azad University, Mashhad Branch, Mashhad, Iran \\ Correspondence should be addressed to Salim Newaz Kazi; salimnewaz@yahoo.com
}

Received 23 April 2014; Revised 16 July 2014; Accepted 25 July 2014; Published 26 August 2014

Academic Editor: Mohammed Hasnaoui

Copyright (C) 2014 Hooman Yarmand et al. This is an open access article distributed under the Creative Commons Attribution License, which permits unrestricted use, distribution, and reproduction in any medium, provided the original work is properly cited.

\begin{abstract}
Thermal characteristics of turbulent nanofluid flow in a rectangular pipe have been investigated numerically. The continuity, momentum, and energy equations were solved by means of a finite volume method (FVM). The symmetrical rectangular channel is heated at the top and bottom at a constant heat flux while the sides walls are insulated. Four different types of nanoparticles $\mathrm{Al}_{2} \mathrm{O}_{3}, \mathrm{ZnO}, \mathrm{CuO}$, and $\mathrm{SiO}_{2}$ at different volume fractions of nanofluids in the range of $1 \%$ to $5 \%$ are considered in the present investigation. In this paper, effect of different Reynolds numbers in the range of $5000<\operatorname{Re}<25000$ on heat transfer characteristics of nanofluids flowing through the channel is investigated. The numerical results indicate that $\mathrm{SiO}_{2}$-water has the highest Nusselt number compared to other nanofluids while it has the lowest heat transfer coefficient due to low thermal conductivity. The Nusselt number increases with the increase of the Reynolds number and the volume fraction of nanoparticles. The results of simulation show a good agreement with the existing experimental correlations.
\end{abstract}

\section{Introduction}

Since nanofluids have shown the capability of transmitting heat more than the conventional fluids, researchers are interested in thermal conductivity which could be useful in many applications including air conditioning and refrigeration. Thus much research has been focusing on this area. Kulkarni et al. [1] represented the use of nanofluids to retard the decrease of cogeneration efficiency. The thermal conductivity of $\mathrm{Cu}$-water nanofluids produced by chemical reduction process was assessed by Liu et al. [2]. The investigation results show $23.8 \%$ enhancement of thermal conductivity at $0.1 \%$ volume fraction of copper particles. Furthermore, it was represented that thermal conductivity increases with particle volume fraction. Hwang et al. [3] reported that the thermal conductivity improvement of nanofluids was remarkably affected by thermal conductivity of both base fluids and nanoparticles. As an example, thermal conductivities of nanofluids produced by multiwalled carbon nanotube and water are greater than those of $\mathrm{SiO}_{2}$-water nanofluids [4]. Yoo et al. [5] pointed out that surface to volume ratio of nanoparticles could be a main factor of influencing the nanofluids thermal conductivity. The thermal conductivity of $\mathrm{Cu}$-water nanofluid was measured by Jana et al. [6]. On the other hand, Kang et al. [7] found a 75\% thermal conductivity improvement for ethylene glycol with $1.2 \%$ diamond nanoparticles of 30 to $50 \mathrm{~nm}$ diameter. In contrast with these improvements, there are some researchers who found some abnormal results. Trivedi [8] found that decreasing the temperature of a component increases its performance such as reliability. Nanofluids have shown their capability as a new generation of coolants for many technological services such as automobile thermal management due to their greater thermal conductivities than the base fluids [9-11]. Vajjha and Das [4] presented dependency of thermal conductivity on both temperature and nanoparticles concentration. They found that it would be more beneficial if nanofluids are employed at high temperature applications. Peng et al. [12] observed that the frictional pressure drop 
of nanorefrigerant boiling flow inside a horizontal smooth pipe is more than that of conventional pure refrigerant which subsequently increases with the increase of volume fraction of nanoparticles. Xie et al. [13] noticed the effect of particle shape on the thermal conductivity. The results were compared with those of suspensions of different geometric shape of the particles with the similar material and base fluid. The report illustrated that the lengthened particles show better enhancement of the thermal conductivity. Touloukian and Makita [14] found experimentally that the volume fraction increase or the nanoparticles size decrease enhances the raise of nanofluid average temperature and decreases the heat transfer coefficient ratio of nanofluids and base fluids. Khanafer et al. [15] studied the heat transfer augmentation in a two-dimensional enclosure by using Nanofluid. The viscosity of the nanofluids was measured by Pantzali et al. [16] and showed double fold increase in comparison with pure water. An increase in the pressure drop and therefore increase in the pumping power were observed. They obtained that the pumping power was increased about $40 \%$ compared to water for a given flow rate.

Haghshenas Fard et al. [17] studied heat transfer efficiency numerically in case of laminar convective heat transfer to nanofluids. They found that the heat transfer coefficient of nanofluids increases with the rise of volume fraction of nanofluids and Peclet number. Similarly laminar mixed convection of $\mathrm{Al}_{2} \mathrm{O}_{3}$-water nanofluid in a horizontal tube under heating at the top half surface of a copper tube was investigated numerically by Allahyari et al. [18]. They observed that increasing of the nanoparticle concentration had remarkably enhanced the heat transfer coefficient whereas the skin friction coefficient was not considerably influenced. The natural convection in an isosceles triangular enclosure was simulated by Aminossadati and Ghasemi [19]. A heat transfer enhancement was observed by them when the solid volume fraction and Rayleigh number were increased. Mahmoudi et al. [20] simulated a cooling system which had been working with natural convection, and they have concluded with a statement that the average Nusselt number increases linearly with the increase of solid volume fraction of nanoparticles. Mansour et al. [21] numerically studied a mixed convection flow in a square lid-driven cavity partially heated from below and filled with different nanofluids to observe the effect of particles type and concentration on heat transfer. They reported that increase in solid volume fraction raises the corresponding average Nusselt number. Shahi et al. [22] analyzed the heat transfer enhancement of a nanofluid by simulation of an annular tube driven by inner heat generating solid cylinder. It has been shown that the average Nusselt numbers were increasingly depending on the solid concentration in the suspension. In addition, Izadi et al. [23] worked on forced convection $\mathrm{Al}_{2} \mathrm{O}_{3}$-water nanofluid flow in an annular tube by simulation. In general the higher nanoparticle volume fraction is added to base fluid, and the more convective heat transfer coefficient is resulted.

Namburu et al. [24] simulated turbulent flow and heat transfer enhancement for three kinds of nanoparticles added to both ethylene glycol and water mixture flowing through a circular pipe. In this study $\kappa-\varepsilon$ turbulent model proposed by Launder and Spalding [25] was adopted. The conclusions illustrated that an increase in concentration of nanofluid is led to rise of the average Nusselt number. Lotfi et al. [26] reported the effect of different models of nanoparticle simulation on forced convection turbulent flow in a circular tube. They made comparisons among three different singlephase, two-phase mixture and Eulerian models. Comparison of the experimental values showed that the mixture model is the most accurate one. Ghaffari et al. [27] studied numerically the turbulent mixed convection heat transfer to $\mathrm{Al}_{2} \mathrm{O}_{3}$-water nanofluid flowing through a horizontal curved pipe with particles size of about $28 \mathrm{~nm}$. The effect of the buoyancy force, centrifugal force, and nanoparticles concentration are assessed in this study. The result illustrated that increases of the nanoparticle volume fraction enhanced the Nusselt number even though its impact on the skin friction coefficient was not remarkable. The turbulent flow of nanofluids with different volume fractions of nanoparticles flowing through a two-dimensional duct under constant heat flux condition was simulated by Rostamani et al. [28]. The results show that both the Nusselt number and the heat transfer coefficient of the nanofluid are strongly dependent on nanoparticles and increased by increasing of the volume concentration of nanoparticles in the suspension. In addition the results presented that, by increasing the volume fraction, the shear stress increases. Recently Fotukian and Nasr Esfahany [29] investigated the turbulent convective heat transfer of dilute $\gamma$ $\mathrm{Al}_{2} \mathrm{O}_{3}$ /water nanofluid inside a circular tube experimentally and found that increasing the volume fraction of nanoparticles in the range of less than $0.2 \%$ provides no significant influence on heat transfer enhancement.

In this paper, an effective single-phase model was applied to study the turbulent forced convection flow of a nanofluid in a uniformly heated rectangular tube. The influence of particles volume fraction and Reynolds number is also studied for each type of particles.

\section{Methodology}

2.1. Governing Equations. It is very important to set the governing equations (momentum, continuity, and energy) to complete the CFD analysis of the rectangular channel. The phenomenon under consideration is governed by the steady two-dimensional form of the continuity, the time-averaged incompressible Navier-Stokes equation, and energy equation. In the certain tensor systems these equations can be written as

continuity equation:

$$
\nabla \cdot\left(\rho_{\mathrm{eff}} U\right)=0
$$

momentum equation:

$$
\nabla \cdot\left(\rho_{\mathrm{eff}} U U\right)=-\nabla P+\nabla\left(\tau+\tau^{T}\right),
$$

energy equation:

$$
\nabla \cdot\left(\rho_{\mathrm{eff}} c_{p, \mathrm{eff}} \bar{T} \bar{U}\right)=\nabla \cdot\left(k_{\mathrm{eff}}(\nabla \bar{T})\right)-\left(\overline{U^{\prime} T^{\prime}}\right) .
$$


TABLE 1: Thermophysical properties of the base fluid and the nanoparticles used in this study $[4,30,31]$.

\begin{tabular}{lccccc}
\hline Property & Pure water & $\mathrm{Al}_{2} \mathrm{O}_{3}$ & $\mathrm{CuO}$ & $\mathrm{SiO}_{2}$ & $\mathrm{ZnO}$ \\
\hline $\begin{array}{l}\text { Density, } \\
\rho\left(\mathrm{kg} / \mathrm{m}^{3}\right)\end{array}$ & 998.2 & 3970 & 6500 & 2200 & 5600 \\
$\begin{array}{l}\text { Specific heat, } \\
C_{p}(\mathrm{~J} / \mathrm{kg} \cdot \mathrm{K})\end{array}$ & 4182 & 765 & 535.6 & 703 & 495.2 \\
$\begin{array}{l}\text { Thermal conductivity, } \\
\mathrm{k}(\mathrm{W} / \mathrm{m} \cdot \mathrm{K})\end{array}$ & 0.6 & 40 & 20 & 1.2 & 13 \\
$\begin{array}{l}\text { Dynamic viscosity, } \\
\mu\left(\mathrm{Ns} / \mathrm{m}^{2}\right)\end{array}$ & 0.001003 & - & - & - & - \\
\hline
\end{tabular}

The standard $k-\varepsilon$ model was employed according to Launder and Spalding [25]:

$$
\begin{aligned}
\nabla \cdot\left(\rho_{\mathrm{eff}} k U\right)= & \nabla \cdot\left[\left(\mu_{\mathrm{eff}}+\frac{\mu_{t}}{\sigma_{k}}\right)(\nabla k)\right]+G_{k}-\rho_{\mathrm{eff}} \varepsilon, \\
\nabla \cdot\left(\rho_{\mathrm{eff}} \varepsilon V\right)= & \nabla \cdot\left[\left(\mu_{\mathrm{eff}}+\frac{\mu_{t}}{\sigma_{\varepsilon}}\right)(\nabla \varepsilon)\right]+C_{1 \varepsilon} \frac{\varepsilon}{k} G_{k} \\
& -C_{2 \varepsilon} \rho_{\mathrm{eff}} \frac{\varepsilon^{2}}{k} \\
G_{k}= & -\rho_{\mathrm{eff}} \overline{u_{i}^{\prime} u_{j}^{\prime}}(\nabla U), \\
\mu_{t}= & \rho_{\mathrm{eff}} C_{\mu} \frac{k^{2}}{\varepsilon}
\end{aligned}
$$

where $C_{\mu}=0.09, \sigma_{k}=1.00, \sigma_{\varepsilon}=1.30, C_{1 \varepsilon}=1.44$, and $C_{2 \varepsilon}=1.92$.

2.2. Physical Properties of Nanofluid. In order to conduct numerical simulation for nanofluids, the effective thermophysical properties of nanofluids must be determined first. In this study, the nanoparticles being used are $\mathrm{Al}_{2} \mathrm{O}_{3}, \mathrm{ZnO}, \mathrm{CuO}$, and $\mathrm{SiO}_{2}$. Thermophysical properties of base fluid and the nanoparticles which are used in the present work are reported in Table 1.

Generally the required properties for numerical simulations are effective thermal conductivity $\left(\mathrm{k}_{\text {eff }}\right)$, effective dynamic viscosity, effective mass density $\left(\rho_{\text {eff }}\right)$, and effective specific heat $\left(C_{p \text { eff }}\right)$. All these effective properties are truly calculated based on the mixing theory.

The density of nanofluid, $\rho_{\mathrm{nf}}$, can be obtained from [32]

$$
\rho_{\mathrm{nf}}=(1-\phi) \rho_{f}+\phi \rho_{s}
$$

where $\rho_{f}$ and $\rho_{\text {np }}$ are the mass densities of the based fluid and the solid nanoparticles, respectively.

The effective heat capacity at constant pressure of nanofluid, $\left(\rho C_{p}\right)_{\mathrm{nf}}$, can be calculated from [33]

$$
\left(\rho C_{p}\right)_{\mathrm{nf}}=(1-\phi)\left(\rho C_{p}\right)_{f}+\phi\left(\rho C_{p}\right)_{s}
$$

where $\left(\rho C_{p}\right)_{f}$ and $\left(\rho C_{p}\right)_{s}$ are heat capacities of the based fluid and the solid nanoparticles, respectively.
The effective viscosity, (7), can be obtained by using the mean empirical correlations suggested by Bianco et al. [33]:

$$
\begin{aligned}
\mu_{\mathrm{eff}} & =\mu_{f} * \frac{1}{\left(1-34.87\left(d_{p} / d_{f}\right)^{-0.3} * \emptyset^{1.03}\right)} \\
d_{f} & =\left[\frac{6 M}{N \pi \rho_{\mathrm{fo}}}\right],
\end{aligned}
$$

where $M$ is the molecular weight of the base fluid, $N$ is the Avogadro number $=6.022 \times 10^{23} \mathrm{moL}^{-1}$, and $\rho_{\mathrm{fo}}$ is the mass density of the base fluid calculated at temperature $T_{0}=$ $300 \mathrm{~K}$. It could be noticed that, for simplicity in this study, the changes of viscosity with temperature along the tube are neglected and the viscosity at all points is considered to be the same as the viscosity at inlet temperature.

By considering Brownian motion of nanoparticles in channel, the effective thermal conductivity can be obtained by using the mean empirical equations (8), (9), and (10) [4]:

$$
K_{\text {eff }}=k_{\text {static }}+k_{\text {Brownian }},
$$

where $k_{\text {static }}$ indicates the thermal conductivity improvement from the advanced thermal conductivity of nanoparticles and $k_{\text {Brownian }}$ represents the effect of Brownian motion of particles. $k_{\text {Brownian }}$ has also considered the influence of movement of fluid particles with nanoparticles. Consider the following:

$$
k_{\text {static }}=k_{f}\left[\frac{\left(k_{s}+2 k_{f}\right)-2 \emptyset\left(k_{f}-k_{s}\right)}{\left(k_{s}+2 k_{f}\right)+\emptyset\left(k_{f}+k_{s}\right)}\right],
$$

where $k_{s}$ and $k_{f}$ are thermal conductivities of the nanoparticles and the base fluid, respectively. Consider the following:

$$
k_{\text {Brawnian }}=5 \times 10^{4} \beta \emptyset \rho_{f} C_{p, f} \sqrt{\frac{K_{B} T}{2 \rho_{s} \cdot R_{s}}} f(T, \emptyset),
$$

where $\rho_{f}$ and $\rho_{s}$ are the densities of the base fluid and the particles, respectively, and $C_{p, f}$ is the specific heat capacity of the base fluid. $K_{B}$ is the Boltzmann constant, $1.381 \times 10^{-23} \mathrm{~J} / \mathrm{k}$. $\beta$ is a parameter which indicates the effect of interaction between nanoparticles and the movement of fluid around the particles. $f(T, \emptyset)$ represents the temperature dependency of nanofluids, where both $f(T, \phi)$ and $\beta$ were obtained by utilizing the existing experimental data.

The modified $f(T, \phi)$ equation was reported by Vajjha and Das [4]:

$$
\begin{aligned}
f(T, \phi) & \\
= & \left(2.8217 \times 10^{-2} \phi+3.917 \times 10^{-3}\right)\left(\frac{T}{273.15}\right) \\
& +\left(-3.0669 \times 10^{-2} \phi-3.91123 \times 10^{-3}\right) .
\end{aligned}
$$

2.3. Simulation Cases. A rectangular pipe with constant heat flux at the wall is considered in this study. The effects of various types of nanofluids are investigated under different volume fractions (1-5\%) and Reynolds number in the range of 5000 to 25000 . Fluid at the entrance has been considered as a constant temperature of $300 \mathrm{~K}$ and uniform axial velocity. 


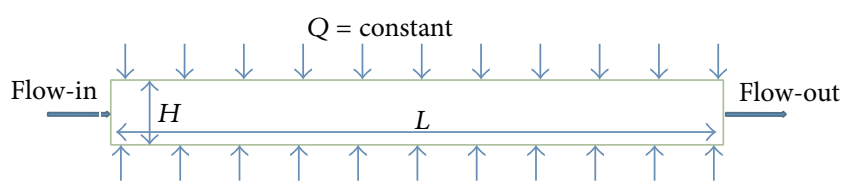

FIGURE 1: Schematic diagram of the rectangular channel.

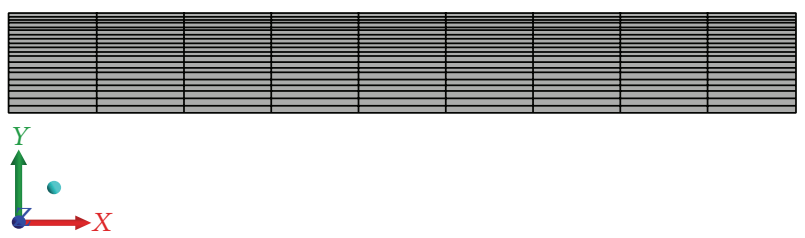

Figure 2: Mesh layout of present geometry, axisymmetric about $X$ axis.

2.4. Numerical Methods. In the present study of heat transfer to turbulent nanofluids in a rectangular duct, the standard $k-\varepsilon$ turbulent model and the Renormalized Group $k-\varepsilon$ turbulence method were used. The time independent incompressible Navier-Stokes equations and the turbulence model analysis were solved by using finite volume method. To evaluate the pressure field, the pressure-velocity coupling algorithm SIMPLE (semi-implicit method for pressure-linked equations) was chosen. The solutions are considered to be converged when the normalized residual values reach $\leq 10^{-5}$ for all parameters.

2.5. Geometry Structure and Boundary Conditions. According to the proposed geometry, the cross section and length are $0.01 \mathrm{~m}^{2}$ and $2 \mathrm{~m}$ respectively. The geometry is simplified to 2-dimenssional planner structure and only half of the pipe is considered for simulation as the upper and lower parts are symmetrical.

The boundary conditions and grid layout for this study are specified for the computational domain as shown in Figures 1 and 2. The top wall is subjected to a constant heat flux of $20000\left(\mathrm{~W} / \mathrm{m}^{2}\right)$ and the bottom wall is symmetry to the top wall. The left side is subjected to velocity inlet and the right side is subjected to pressure outlet.

\section{Results and Discussion}

3.1. Mesh Dependency Test and Validation. Several different grid distributions have been tested to ensure that the calculated results ( $\mathrm{Nu}$ numbers) are grid independent (Figure 3 ). The $\mathrm{Nu}$ numbers are calculated based on the simulation results as follows:

$$
\mathrm{Nu}=\frac{h \cdot D_{h}}{k_{\mathrm{eff}}}=\frac{q^{\prime \prime} \cdot D_{h}}{\left(T_{w}-T\right) \cdot k_{\mathrm{eff}}},
$$

where $h, D_{h}, T_{w}$, and $q^{\prime \prime}$ are heat transfer coefficient, hydraulic diameter, wall temperature, and heat flux, respectively.

Equations (13)-(17) are used for evaluation of Nusselt number for water and nanofluids. Here (15)-(17) are specifically used for calculations of Nusselt number of water

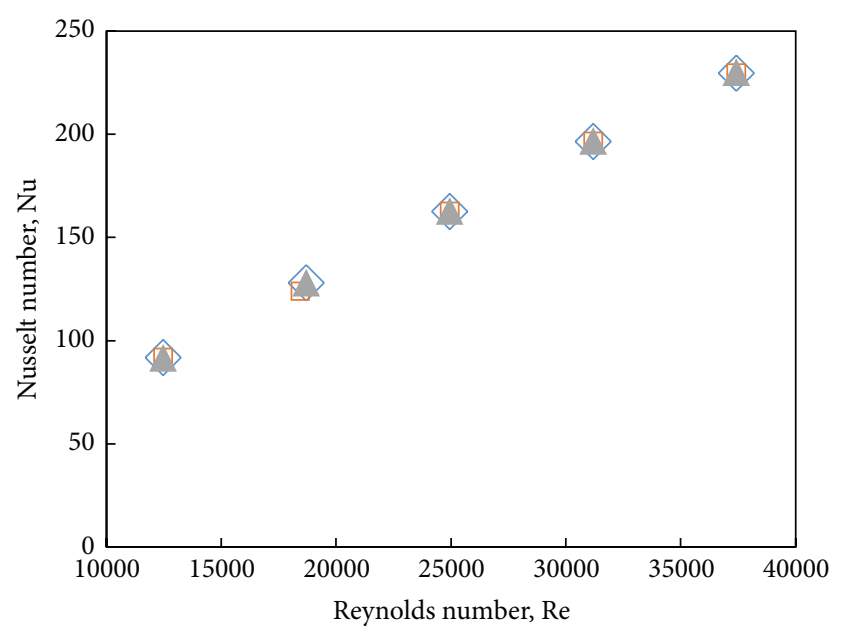

$$
\begin{aligned}
& \triangle 2000 \times 50 \\
& \square 2250 \times 60 \\
& \triangle 2500 \times 70
\end{aligned}
$$

Figure 3: Comparison of the Nusselt number for water with different grids.

whereas (13)-(17) are applied for calculating the Nusselt number of nanofluids.

Maïga et al. [34] equation for nanofluid:

$$
\mathrm{Nu}=0.085 \operatorname{Re}^{0.71} \operatorname{Pr}^{0.35} .
$$

Pak and Cho [35] equation for nanofluid:

$$
\mathrm{Nu}=0.021 \mathrm{Re}^{0.8} \operatorname{Pr}^{0.5} \text {. }
$$

Dittus and Boelter [36] equation for water and nanofluid:

$$
\mathrm{Nu}=0.023 \operatorname{Re}^{0.8} \operatorname{Pr}^{0.4} \text {. }
$$

Bejan [37] equation for water and nanofluid:

$$
\mathrm{Nu}=0.021\left(\operatorname{Re}^{0.87}-280\right) \operatorname{Pr}^{0.4}
$$

Gnielinski [38] equation for water and nanofluid:

$$
\mathrm{Nu}=\frac{(f / 8)(\operatorname{Re}-1000) \operatorname{Pr}}{1+12.7(f / 8)^{0.5}\left(\operatorname{Pr}^{2 / 3}-1\right)},
$$

where $f=(0.79 \ln \operatorname{Re}-1.64)^{-2}$.

According to Figure 3, it is observed that the calculated Nusselt number for base fluid (water) is independent of the number of grid points. The selected grid consists of 2000 and 50 nodes in the $x$ and $y$ directions, respectively. The maximum deviation of the selected mesh relative to the two other finer meshes (i.e., $22250 \times 60$ and $2500 \times 70$ ) is less than $0.6 \%$.

The selected residual value is $10^{-5}$ for less computational effort. Since the less residual value might influence the accuracy of the results, the residual sensitivity test has been done to assess the effect of this value. According to Figure 4 the predicted $\mathrm{Nu}$ number of water by the CFD model considering 


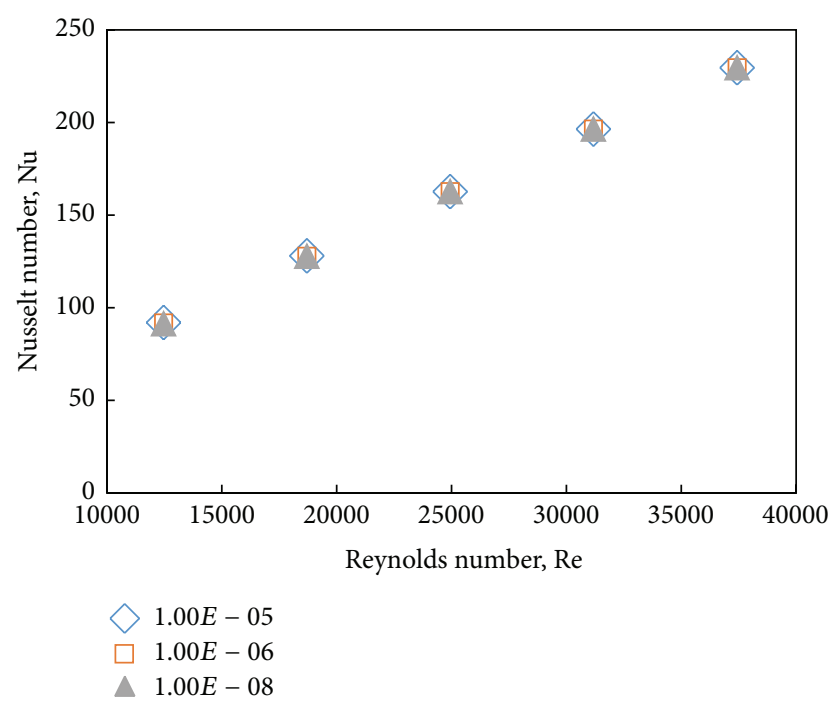

FIgURE 4: Residual sensitivity test for water.

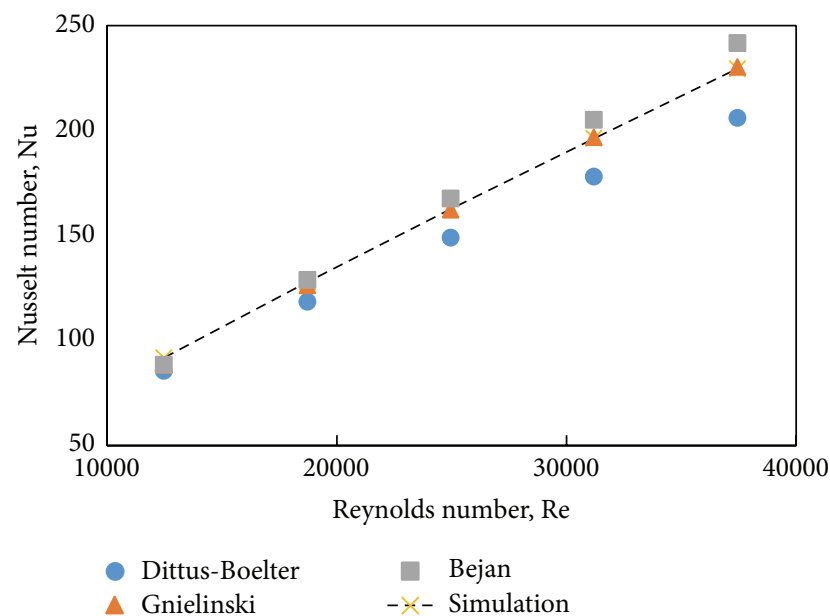

Figure 5: Comparison of Nusselt number from computed values and benchmarks for water.

residual value of $10^{-5}$ shows no significant deviation from those with $10^{-6}$ and $10^{-8}$ residual values.

To justify the computational model, evaluated numerical results are compared with the calculated data from some empirical correlations. Figure 5 represents the comparison between the evaluated Nusselt number and the calculated values from the three different empirical correlations such as Gnielinski [38], Dittus and Boelter [36], and Bejan [37]. It can be seen that the numerical Nusselt numbers for water are in a good agreement with the benchmarks. There is a slight deviation which could be considered negligible in validation. The average deviation of estimated data and Dittus and Boelter data is $9.61 \%$ but the average deviation of Gnielinski and Bejan correlation data and simulation result is $0.45 \%$ and $5 \%$, respectively, indicating that the model could be used for heat transfer calculations with reasonable accuracy.

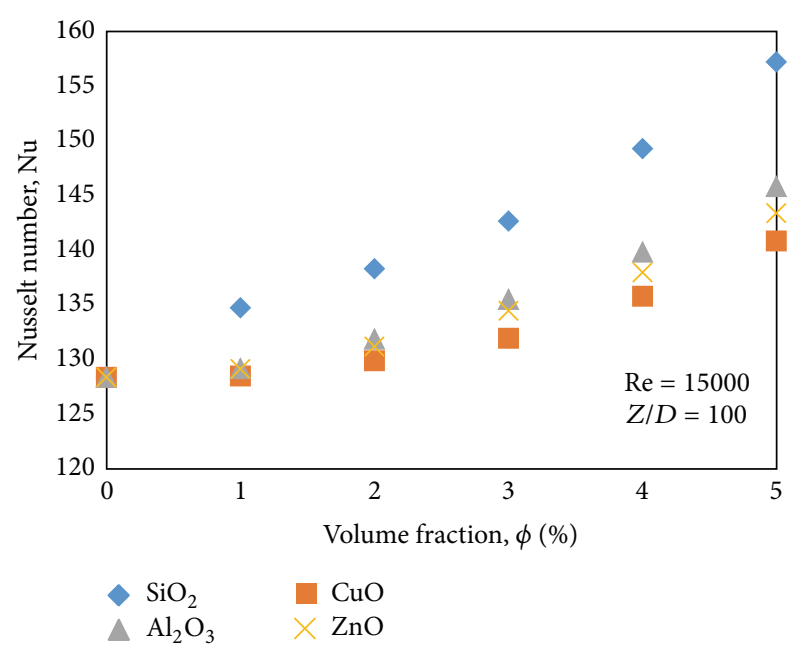

FIGURE 6: Effect of volume concentrations of different nanoparticles on Nusselt number.

3.2. Effect of Nanoparticles with Different Volume Concentrations on the Nusselt Number and Heat Transfer Coefficient. The effect of volume concentrations of different types of nanoparticles on the Nusselt number is presented in Figure 6. The Reynolds number is 15000 and the volume concentrations varied as $1 \%, 2 \%, 3 \%, 4 \%$, and $5 \%$. The results show that with the increase of concentration of nanoparticles in the base fluid the Nusselt number increases. In addition $\mathrm{SiO}_{2}$ water nanofluid shows the most enhancement of Nusselt number, while the other nanoparticles $\left(\mathrm{Al}_{2} \mathrm{O}_{3}, \mathrm{ZnO}\right.$, and $\mathrm{CuO}$ ) have little variation of Nusselt numbers at all the volume fractions. It should be noted that the Gnielinski formula is more accurate than Dittus and Boelter correlation, so the discrepancies between simulated results and Gnielinski equation are presented in Table 2. As it is illustrated simulated results are in good agreement with the correlations.

In addition to this, for more comprehensive comparison, the simulation results for $\mathrm{Al}_{2} \mathrm{O}_{3}$-water nanofluid at $\mathrm{Re}=$ 15,000 and at different nanoparticle concentrations (1\%-5\%) are benchmarked against the data from some empirical correlations (i.e., [34-36, 38]). According to Figure 7, although the simulation results give a good agreement with the all correlations, as expected, the Pak and Cho correlation shows the closest answer to the simulation results.

Figure 8 shows the effect of different concentrations of the selected nanoparticles on heat transfer coefficient. Since the dimensionless function Nusselt number shows the ratio of convection mechanism to conduction one for each kind of fluid, it is not reliable for comparison of only Nusselt number of different nanofluids. For instance, $\mathrm{SiO}_{2}$ has the maximum Nusselt number while it shows the least heat transfer coefficient due to the lowest thermal conductivity. In this case $\mathrm{Al}_{2} \mathrm{O}_{3}$ shows the maximum heat transfer coefficient while $\mathrm{CuO}$ and $\mathrm{ZnO}$ are after it with a slight difference. on the Nusselt Number and Heat Transfer Coefficient. The 
TABLE 2: Comparison between the computed data of Nusselt numbers and the data from two benchmarks at different concentrations for $\mathrm{SiO}_{2} /$ water.

\begin{tabular}{lcccc}
\hline & & \multicolumn{2}{c}{$\mathrm{SiO}_{2} /$ water, $\mathrm{Re}=15000$} \\
Concentration & $\mathrm{Nu}$ (simulation) & $\mathrm{Nu}$ (Dittus-Boelter) & $\mathrm{Nu}$ (Gnielinski) & Discrepancy between simulation and Gnielinski \\
\hline $1 \%$ & 134.71 & 112.83 & 117.97 & $12.43 \%$ \\
$2 \%$ & 138.26 & 116.61 & 121.76 & $11.93 \%$ \\
$3 \%$ & 142.64 & 121.42 & 126.55 & $11.28 \%$ \\
$4 \%$ & 149.27 & 127.47 & 132.50 & $11.23 \%$ \\
$5 \%$ & 157.19 & 135.32 & 140.13 & $10.85 \%$ \\
\hline
\end{tabular}

TABLE 3: The comparison between prediction of Nusselt number and benchmarks at $\phi=3 \%$ and different Reynolds numbers for $\mathrm{SiO}_{2}$ nanoparticles.

\begin{tabular}{lcccc}
\hline & & & $\mathrm{SiO}_{2} /$ water (3\%) \\
$\mathrm{Re}$ & $\mathrm{Nu}$ (Simulation) & $\mathrm{Nu}$ (Dittus-Boelter) & $\mathrm{Nu}$ (Gnielinski) & Discrepancy between simulation and Gnielinski \\
\hline 5000 & 59.25 & 50.41 & 44.16 & $25.47 \%$ \\
10000 & 102.18 & 87.78 & 87.31 & $14.55 \%$ \\
15000 & 142.64 & 121.41 & 126.55 & $11.28 \%$ \\
20000 & 181.69 & 152.83 & 163.65 & $9.93 \%$ \\
25000 & 219.86 & 182.70 & 199.32 & $9.34 \%$ \\
\hline
\end{tabular}

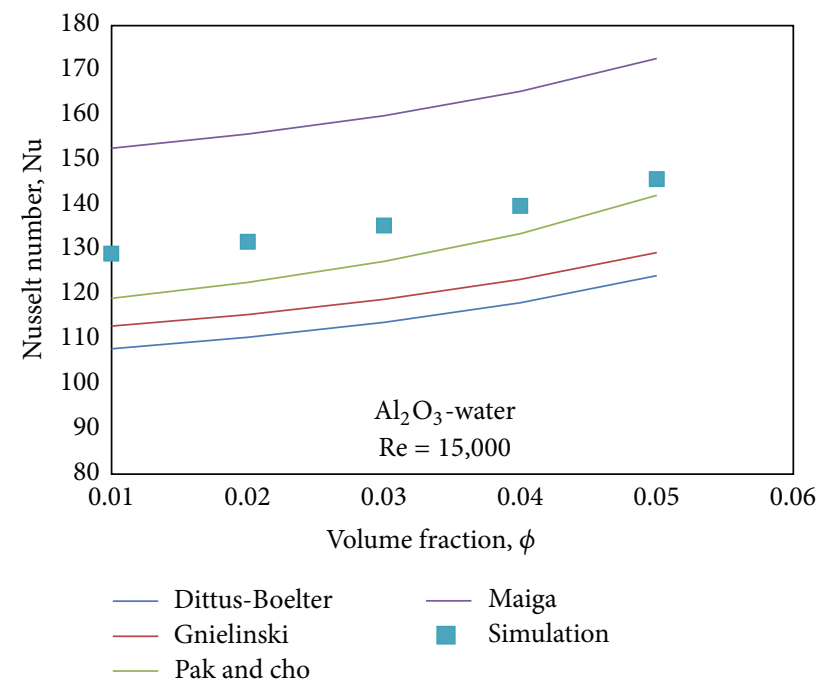

FIgURE 7: Comparison between the computed data of Nusselt numbers and the data from four benchmarks at different concentrations for $\mathrm{Al}_{2} \mathrm{O}_{3}$-water.

effective thermophysical properties of the different nanofluids are used at a constant volume fraction of $3 \%$ but at different inlet velocities or Reynolds numbers varied from 5000 to 25000 .

Figures 9 and 10 illustrate that with the increase of Reynolds number the Nusselt number and heat transfer coefficient also increase. Similar to the results obtained in the Figures 6 and 8, where $\mathrm{SiO}_{2}$-water has the highest Nusselt number but it shows the least heat transfer coefficient. Slopes of the graphs in Figures 9 and 10 are higher than slopes of the graphs in Figures 6 and 8, so it can be concluded that the changes of Nusselt number and heat transfer coefficient

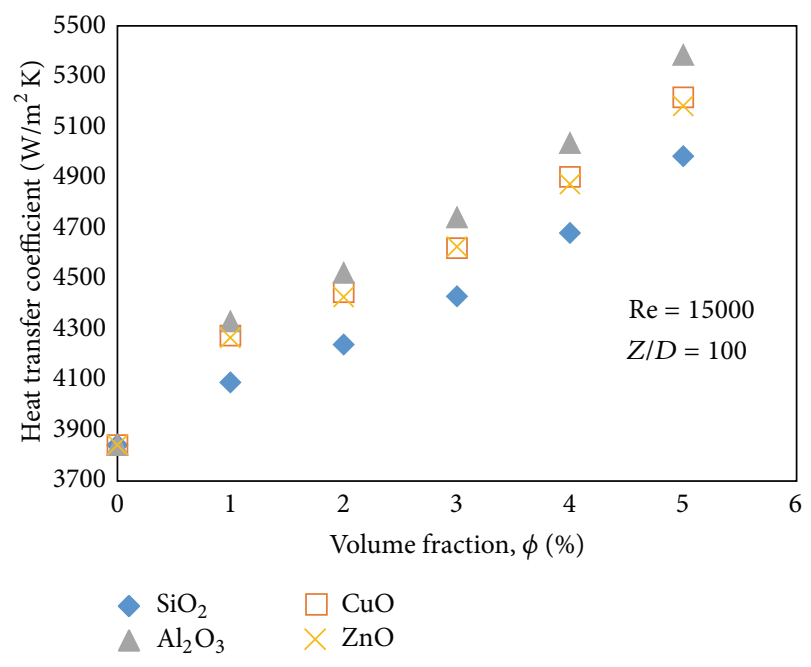

FIGURE 8: Effect of volume concentrations of nanoparticles on heat transfer coefficient.

are more sensitive to the Reynolds number than the volume fraction.

Moreover, discrepancies between simulated results and Gnielinski correlation for $\mathrm{SiO}_{2}$-water are shown in Table 3 . According to the obtained discrepancies, it is concluded that the use of Gnielinski correlation to calculate the Nusselt number for nanofluids is more practical for Reynolds number greater than $10^{4}$ [24].

In addition to this, for more comprehensive comparison, the simulation results of $\mathrm{Al}_{2} \mathrm{O}_{3}$-water nanofluid, $\phi=3 \%$ and at different Re numbers (5000-25000) are benchmarked against some empirical correlations (Figure 11). Although the simulation results give a good agreement with all the correlations, as expected, the simulation results are between 


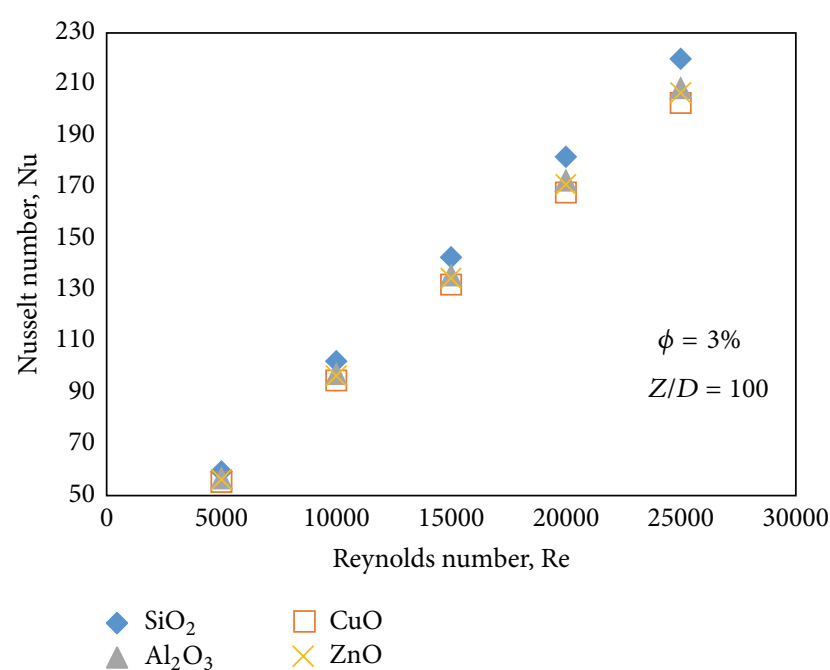

FIGURE 9: Nusselt number of different types of water based nanofluids at different Reynolds numbers.

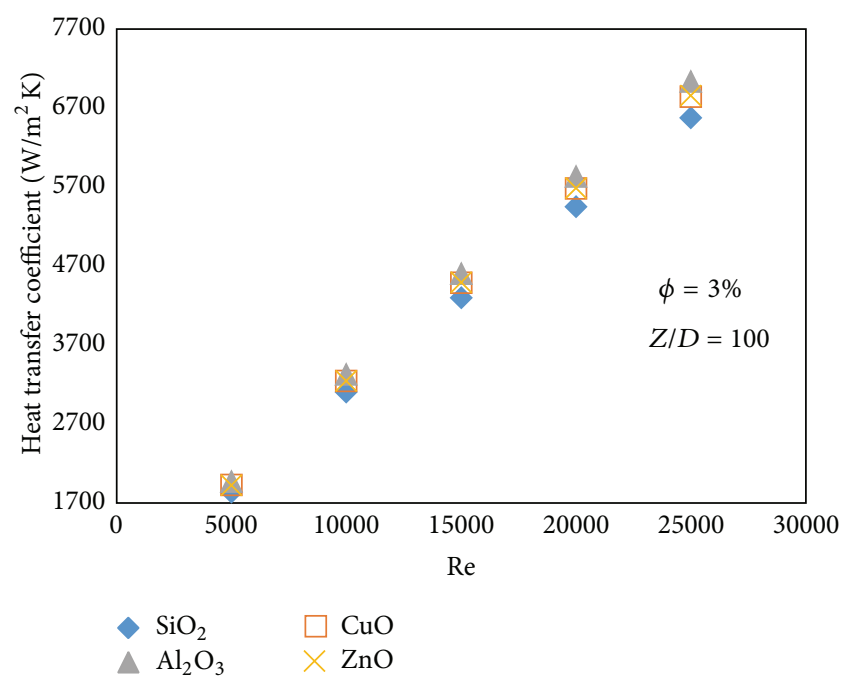

FIGURE 10: Heat transfer coefficient of different types of water based nanofluids at different Reynolds numbers.

the Pak and Cho correlation and Maiga correlation. The Pak and Cho correlation shows the closest data to the simulation results.

\section{Conclusions}

Numerical simulation of turbulent forced convection heat transfer in a rectangular heated pipe was performed in the present study. The emphasis was given on the heat transfer enhancement resulting from various parameters which include different types of nanofluids $\left(\mathrm{Al}_{2} \mathrm{O}_{3}, \mathrm{CuO}, \mathrm{SiO}_{2}\right.$, and $\mathrm{ZnO}$ ), volume fraction of nanoparticles in the range of $1 \%<$ $\phi<5 \%$ and the Reynolds number in the range of $5000<\operatorname{Re}<$ 25000 . The governing equations were solved by utilizing finite volume method with certain assumptions and appropriate boundary conditions to provide a clear understanding of the

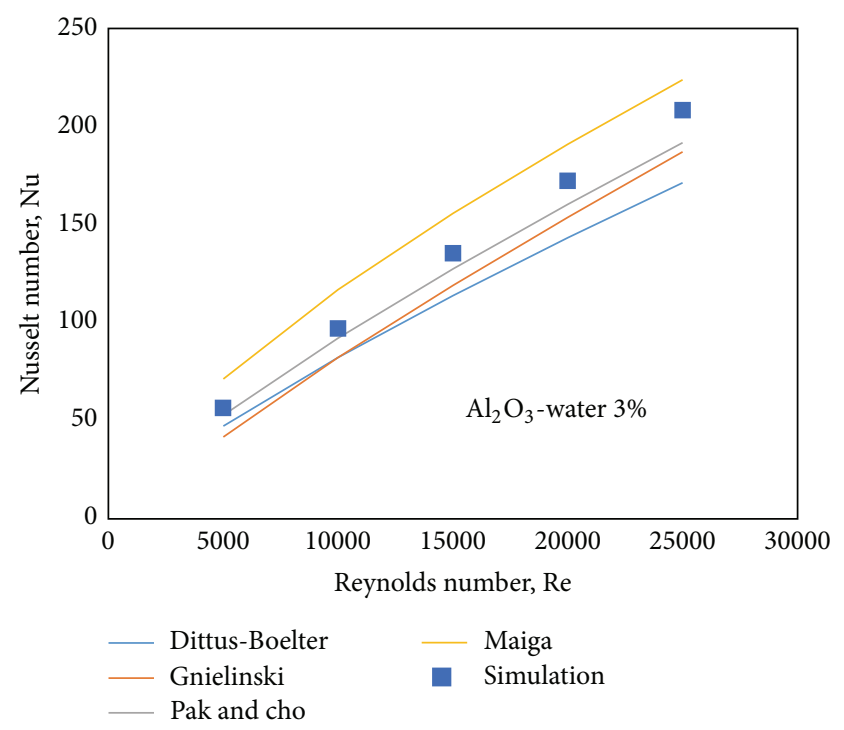

Figure 11: Comparison between the computed data of Nusselt numbers and the data from four benchmarks at different Re numbers for $\mathrm{Al}_{2} \mathrm{O}_{3}$-water $3 \%$ nanofluid.

modeling aims and conditions for the present study. CFD software (ANSYS-FLUENT) has been employed in this study to simulate the current results. The following conclusions could be drawn from the present investigation.

(1) Among the investigated nanofluids $\mathrm{SiO}_{2}$ generates the highest Nusselt number followed by $\mathrm{Al}_{2} \mathrm{O}_{3}, \mathrm{ZnO}$, $\mathrm{CuO}$, and the pure water.

(2) Although $\mathrm{SiO}_{2}$ has the highest Nusselt number, it has the least heat transfer coefficient because of the lowest thermal conductivity among the tested nanofluids.

(3) The Nusselt number increases gradually with the increase of the volume fraction of nanoparticles and Reynolds number.

(4) Effect of Reynolds number is more dominant than concentration effect of nanoparticles on heat transfer to nanofluids.

(5) The advent of computational fluid dynamic software (Fluent) could provide fair and agreeable result from experimental correlations as noticed in the present research.

\section{Nomenclature}

\section{Roman Symbols}

$C_{p}$ : Specific heat capacity at constant pressure $(\mathrm{J} / \mathrm{kg} \cdot \mathrm{K})$

$D_{h}:$ Hydraulic diameter $(\mathrm{m})$

$d_{p}:$ Nanoparticle diameter $(\mathrm{m})$

$h$ : Heat transfer coefficient based on mean temperature $\left(\mathrm{W} / \mathrm{m}^{2} \mathrm{k}\right)$

I: Turbulent intensity

$I_{0}$ : Initial turbulent intensity 
$k$ : Turbulence kinetic energy $\left(\mathrm{m}^{2} / \mathrm{s}^{2}\right)$

k: Thermal conductivity (W/m K)

$\mathrm{Nu}$ : Nusselt number $\left(h \cdot D_{h} / k\right)$

p: $\quad$ Static pressure $\left(\mathrm{N} / \mathrm{m}^{2}\right)$

Pr: Liquid Prandtl number

$q^{\prime \prime}:$ Heat flux $\left(\mathrm{W} / \mathrm{m}^{2}\right)$

$\mathrm{Re}_{h}$ : Reynolds number $\left(\rho v_{\text {in }} D_{h} / \mu\right)$

$T: \quad$ Temperature $(\mathrm{K})$

$T^{\prime}$ : Fluctuating part of temperature $(\mathrm{K})$

$v: \quad$ Velocity $(\mathrm{m} / \mathrm{s})$

$v^{\prime}$ : Fluctuating part of velocity $(\mathrm{m} / \mathrm{s})$.

\section{Greek Letters}

$\varepsilon:$ Dissipation rate of turbulence kinetic energy $\left(\mathrm{m}^{2} / \mathrm{s}^{3}\right)$

$\mu$ : Dynamic viscosity $(\mathrm{kg} / \mathrm{m} \mathrm{s})$

$\mu_{t}$ : Turbulent viscosity $(\mathrm{kg} / \mathrm{m} \mathrm{s})$

$\rho$ : Density $\left(\mathrm{kg} / \mathrm{m}^{3}\right)$

$v$ : Kinematic viscosity

$\phi$ : Particle volume fraction.

\section{Subscriptions}

eff: Effective

$f$ : Fluid

p: Particle phase

$s:$ Solid

$w$ : Wall

$z:$ Axial direction

-: Mean

0 : Initial.

\section{Conflict of Interests}

The authors declare that there is no conflict of interests regarding the publication of this paper.

\section{Acknowledgment}

The authors gratefully acknowledge High Impact Research Grant UM.C/HIR/MOHE/ENG/45 and the UMRG Fund RP012D-13AET, University of Malaya, Malaysia, for support to conduct this research work.

\section{References}

[1] D. P. Kulkarni, D. K. Das, and G. A. Chukwu, “Temperature dependent rheological property of copper oxide nanoparticles suspension (nanofluid)," Journal of Nanoscience and Nanotechnology, vol. 6, no. 4, pp. 1150-1154, 2006.

[2] M.-S. Liu, M.-C. Lin, C. Y. Tsai, and C.-C. Wang, "Enhancement of thermal conductivity with $\mathrm{Cu}$ for nanofluids using chemical reduction method," International Journal of Heat and Mass Transfer, vol. 49, no. 17-18, pp. 3028-3033, 2006.

[3] Y. J. Hwang, Y. C. Ahn, H. S. Shin et al., "Investigation on characteristics of thermal conductivity enhancement of nanofluids," Current Applied Physics, vol. 6, no. 6, pp. 1068-1071, 2006.
[4] R. S. Vajjha and D. K. Das, "Experimental determination of thermal conductivity of three nanofluids and development of new correlations," International Journal of Heat and Mass Transfer, vol. 52, no. 21-22, pp. 4675-4682, 2009.

[5] D. Yoo, K. S. Hong, and H. Yang, "Study of thermal conductivity of nanofluids for the application of heat transfer fluids," Thermochimica Acta, vol. 455, no. 1-2, pp. 66-69, 2007.

[6] S. Jana, A. Salehi-Khojin, and W.-H. Zhong, "Enhancement of fluid thermal conductivity by the addition of single and hybrid nano-additives," Thermochimica Acta, vol. 462, no. 1-2, pp. 45$55,2007$.

[7] H. U. Kang, S. H. Kim, and J. M. Oh, "Estimation of thermal conductivity of nanofluid using experimental effective particle volume," Experimental Heat Transfer, vol. 19, no. 3, pp. 181-191, 2006.

[8] A. Trivedi, Thermo-Mechanical Solutions in Electronic Packaging: Component to System Level, 2008.

[9] M. R. Safaei, H. R. Goshayeshi, B. S. Razavi, and M. Goodarzi, "Numerical investigation of laminar and turbulent mixed convection in a shallow water-filled enclosure by various turbulence methods," Scientific Research and Essays, vol. 6, no. 22, pp. 48264838, 2011.

[10] C. Choi, H. S. Yoo, and J. M. Oh, "Preparation and heat transfer properties of nanoparticle-in-transformer oil dispersions as advanced energy-efficient coolants," Current Applied Physics, vol. 8, no. 6, pp. 710-712, 2008.

[11] M. Goodarzi, M. Safaei, K. Vafai et al., "Investigation of nanofluid mixed convection in a shallow cavity using a twophase mixture model," International Journal of Thermal Sciences, vol. 75, pp. 204-220, 2014.

[12] H. Peng, G. Ding, W. Jiang, H. Hu, and Y. Gao, "Measurement and correlation of frictional pressure drop of refrigerantbased nanofluid flow boiling inside a horizontal smooth tube," International Journal of Refrigeration, vol. 32, no. 7, pp. 1756$1764,2009$.

[13] H. Xie, J. Wang, T. Xi, Y. Liu, F. Ai, and Q. Wu, “Thermal conductivity enhancement of suspensions containing nanosized alumina particles," Journal of Applied Physics, vol. 91, no. 7, pp. 4568-4572, 2002.

[14] Y. S. Touloukian and T. Makita, Thermophysical Properties of Matter-The TPRC Data Series, vol. 6 of Specific Heat-Nonmetallic Liquids and Gases, DTIC Document, 1970.

[15] K. Khanafer, K. Vafai, and M. Lightstone, "Buoyancy-driven heat transfer enhancement in a two-dimensional enclosure utilizing nanofluids," International Journal of Heat and Mass Transfer, vol. 46, no. 19, pp. 3639-3653, 2003.

[16] M. N. Pantzali, A. A. Mouza, and S. V. Paras, "Investigating the efficacy of nanofluids as coolants in plate heat exchangers (PHE)," Chemical Engineering Science, vol. 64, no. 14, pp. 3290 3300, 2009.

[17] M. Haghshenas Fard, M. N. Esfahany, and M. R. Talaie, "Numerical study of convective heat transfer of nanofluids in a circular tube two-phase model versus single-phase model," International Communications in Heat and Mass Transfer, vol. 37, no. 1, pp. 91-97, 2010.

[18] S. Allahyari, A. Behzadmehr, and S. M. Hosseini Sarvari, "Conjugate heat transfer of laminar mixed convection of a nanofluid through a horizontal tube with circumferentially non-uniform heating," International Journal of Thermal Sciences, vol. 50, no. 10, pp. 1963-1972, 2011.

[19] S. M. Aminossadati and B. Ghasemi, "Enhanced natural convection in an isosceles triangular enclosure filled with a 
nanofluid," Computers and Mathematics with Applications, vol. 61, no. 7, pp. 1739-1753, 2011.

[20] A. H. Mahmoudi, M. Shahi, A. H. Raouf, and A. Ghasemian, "Numerical study of natural convection cooling of horizontal heat source mounted in a square cavity filled with nanofluid," International Communications in Heat and Mass Transfer, vol. 37, no. 8, pp. 1135-1141, 2010.

[21] M. A. Mansour, R. A. Mohamed, M. M. Abd-Elaziz, and S. E. Ahmed, "Numerical simulation of mixed convection flows in a square lid-driven cavity partially heated from below using nanofluid," International Communications in Heat and Mass Transfer, vol. 37, no. 10, pp. 1504-1512, 2010.

[22] M. Shahi, A. H. Mahmoudi, and F. Talebi, "A numerical investigation of conjugated-natural convection heat transfer enhancement of a nanofluid in an annular tube driven by inner heat generating solid cylinder," International Communications in Heat and Mass Transfer, vol. 38, no. 4, pp. 533-542, 2011.

[23] M. Izadi, A. Behzadmehr, and D. Jalali-Vahida, "Numerical study of developing laminar forced convection of a nanofluid in an annulus," International Journal of Thermal Sciences, vol. 48, no. 11, pp. 2119-2129, 2009.

[24] P. K. Namburu, D. K. Das, K. M. Tanguturi, and R. S. Vajjha, "Numerical study of turbulent flow and heat transfer characteristics of nanofluids considering variable properties," International Journal of Thermal Sciences, vol. 48, no. 2, pp. 290302, 2009.

[25] B. E. Launder and D. B. Spalding, "The numerical computation of turbulent flows," Computer Methods in Applied Mechanics and Engineering, vol. 3, no. 2, pp. 269-289, 1974.

[26] R. Lotfi, Y. Saboohi, and A. M. Rashidi, "Numerical study of forced convective heat transfer of nanofluids: comparison of different approaches," International Communications in Heat and Mass Transfer, vol. 37, no. 1, pp. 74-78, 2010.

[27] O. Ghaffari, A. Behzadmehr, and H. Ajam, "Turbulent mixed convection of a nanofluid in a horizontal curved tube using a two-phase approach," International Communications in Heat and Mass Transfer, vol. 37, no. 10, pp. 1551-1558, 2010.

[28] M. Rostamani, S. F. Hosseinizadeh, M. Gorji, and J. M. Khodadadi, "Numerical study of turbulent forced convection flow of nanofluids in a long horizontal duct considering variable properties," International Communications in Heat and Mass Transfer, vol. 37, no. 10, pp. 1426-1431, 2010.

[29] S. M. Fotukian and M. Nasr Esfahany, "Experimental investigation of turbulent convective heat transfer of dilute $\gamma$ $\mathrm{Al}_{2} \mathrm{O}_{3}$ /water nanofluid inside a circular tube," International Journal of Heat and Fluid Flow, vol. 31, no. 4, pp. 606-612, 2010.

[30] R. S. Vajjha, D. K. Das, and D. P. Kulkarni, "Development of new correlations for convective heat transfer and friction factor in turbulent regime for nanofluids," International Journal of Heat and Mass Transfer, vol. 53, no. 21-22, pp. 4607-4618, 2010.

[31] J. H. Lienhard and J. Lienhard, A Heat Transfer Textbook, Phlogiston Press, Cambridge, Mass, USA, 2000.

[32] K. A. Hoffmann and S. T. Chiang, Computational Fluid Dynamics, vol. 1, Engineering Education System, Wichita, Kan, USA, 2000.

[33] V. Bianco, F. Chiacchio, O. Manca, and S. Nardini, "Numerical investigation of nanofluids forced convection in circular tubes," Applied Thermal Engineering, vol. 29, no. 17-18, pp. 3632-3642, 2009.

[34] S. E. B. Maïga, C. T. Nguyen, N. Galanis, G. Roy, T. Maré, and M. Coqueux, "Heat transfer enhancement in turbulent tube flow using $\mathrm{Al}_{2} \mathrm{O}_{3}$ nanoparticle suspension," International Journal of Numerical Methods for Heat and Fluid Flow, vol. 16, no. 3, pp. 275-292, 2006.

[35] B. C. Pak and Y. I. Cho, "Hydrodynamic and heat transfer study of dispersed fluids with submicron metallic oxide particles," Experimental Heat Transfer, vol. 11, no. 2, pp. 151-170, 1998.

[36] F. W. Dittus and L. M. K. Boelter, Heat Transfer for Automobile Radiators of the Tubular Type, vol. 2 of University of California Publications in Engineering, University of California Press, 1930.

[37] A. Bejan, Heat Transfer, John Wiley \& Sons, New York, NY, USA, 1993.

[38] V. Gnielinski, "New equations for heat and mass transfer in the turbulent flow in pipes and channels," NASA STI/Recon Technical Report A 75, 1975. 

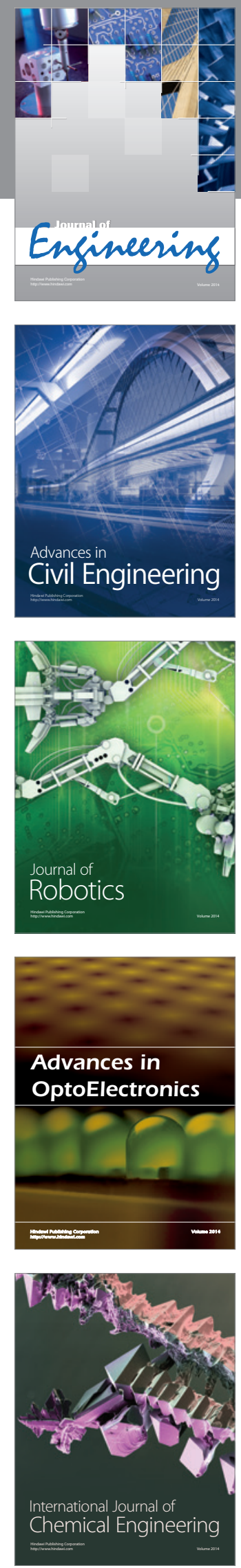

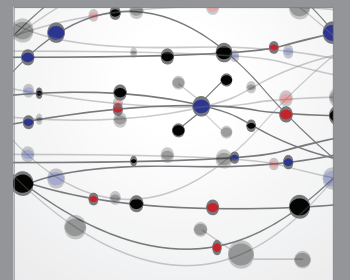

The Scientific World Journal
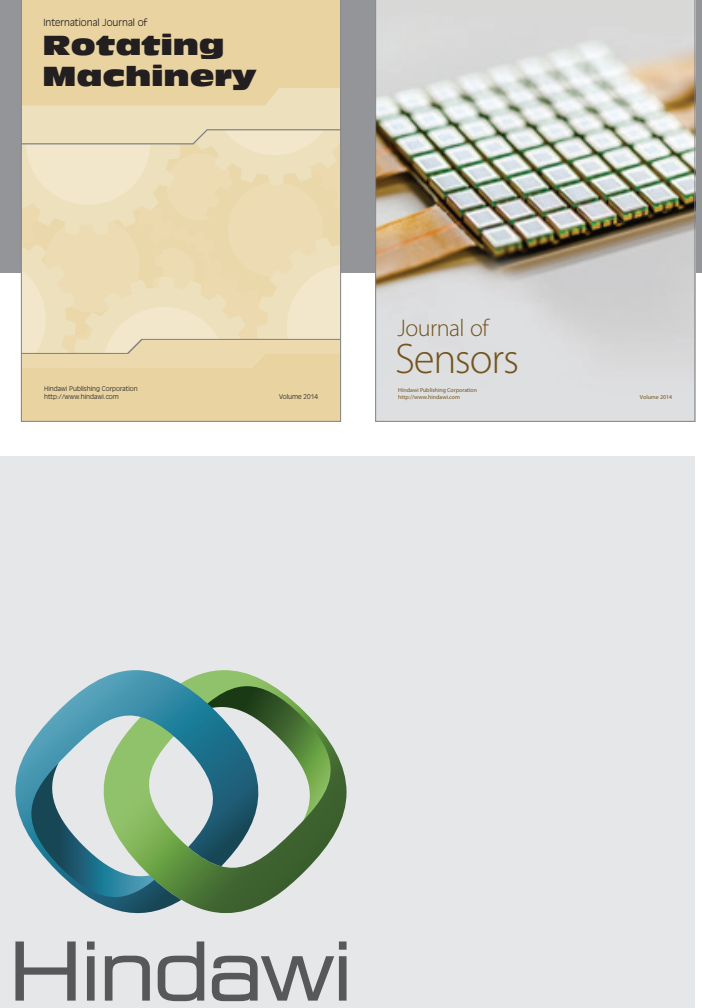

Submit your manuscripts at http://www.hindawi.com
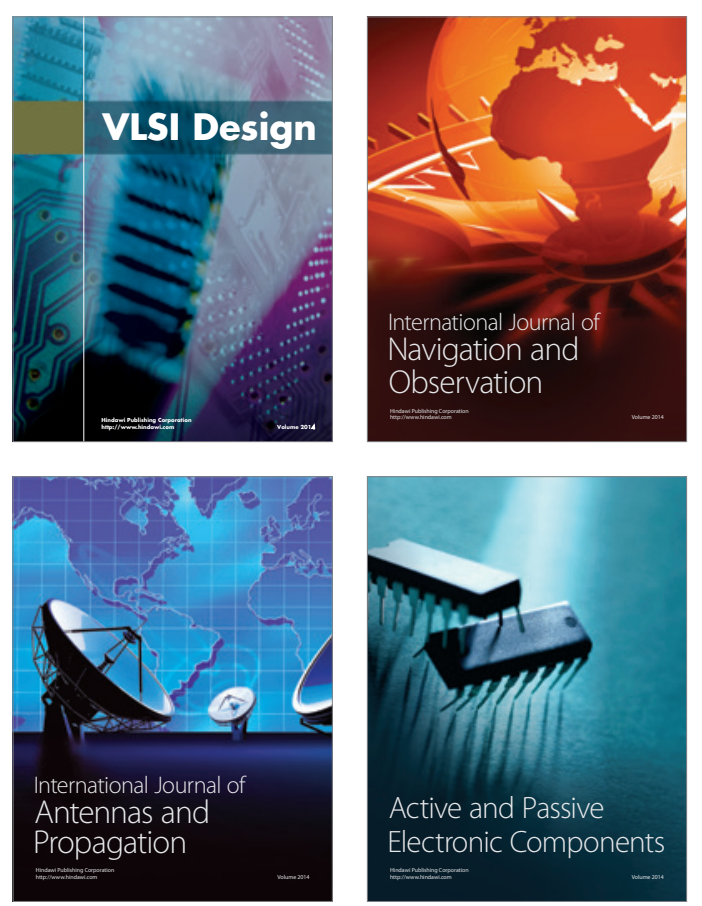
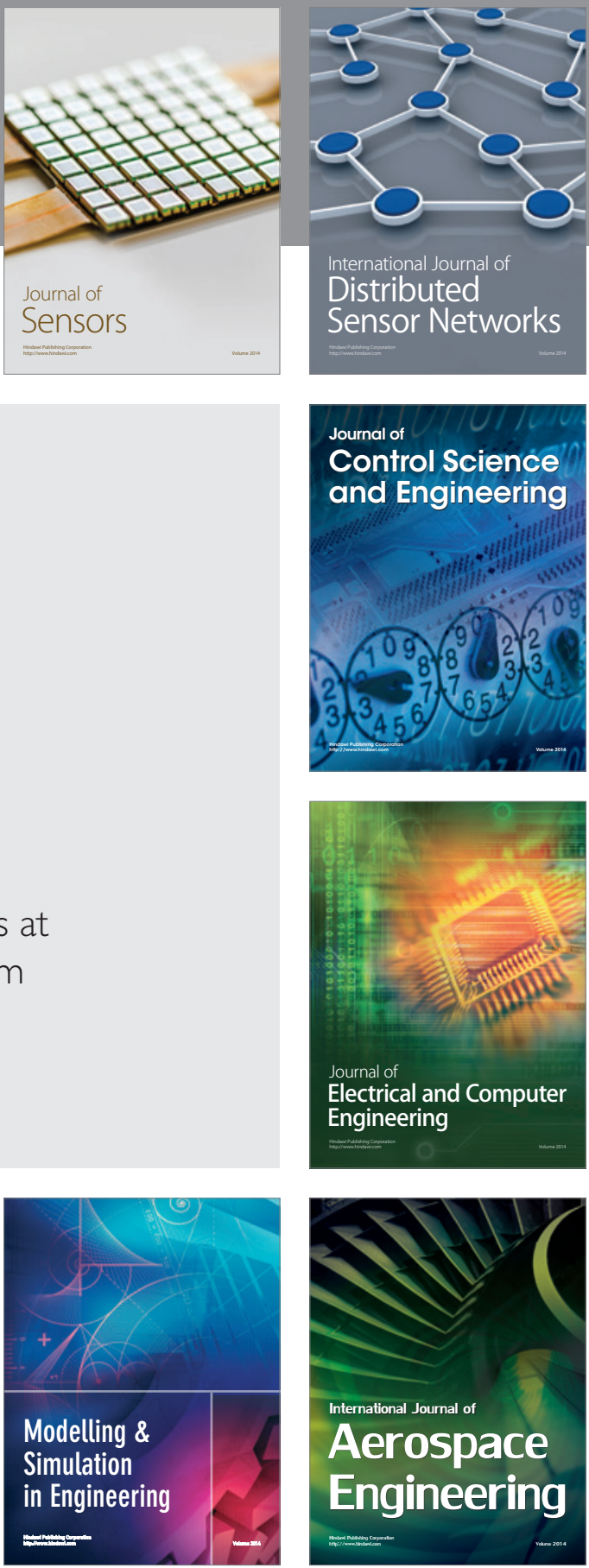

Journal of

Control Science

and Engineering
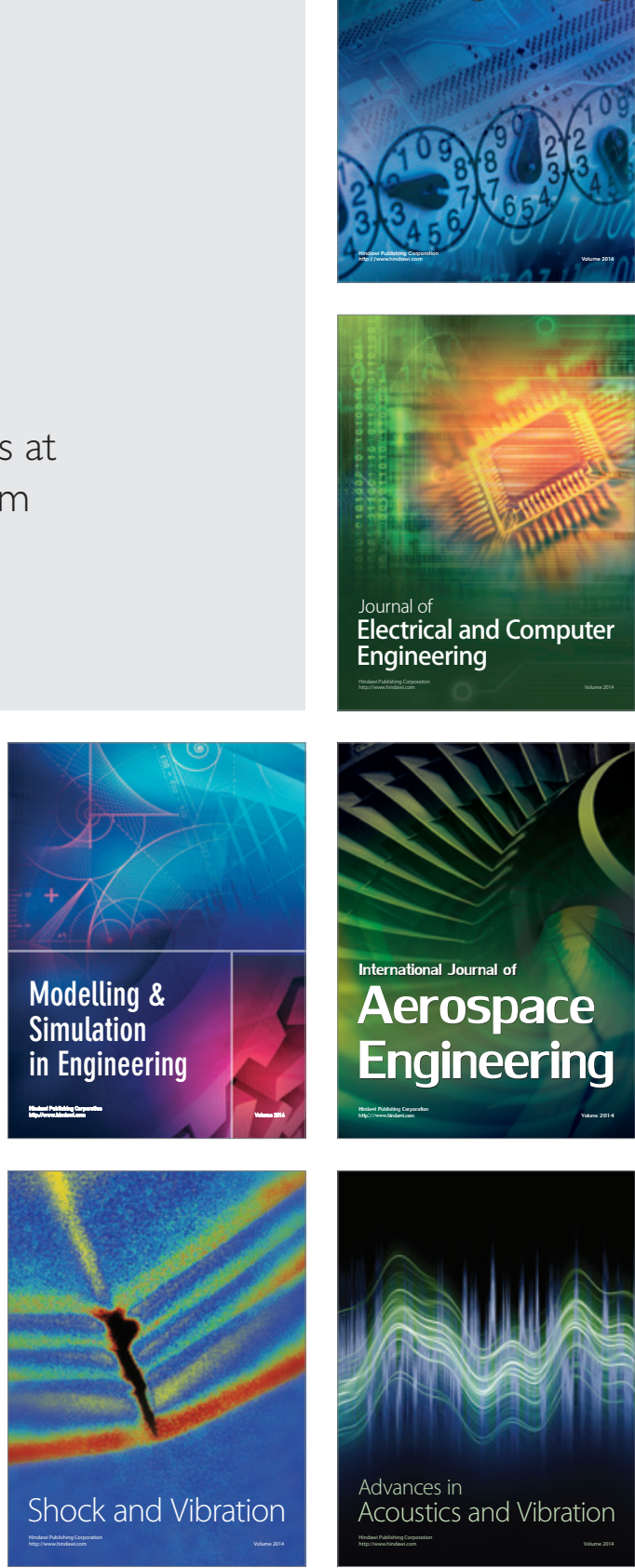